\title{
A new lung donor score to predict short and long-term survival in lung transplantation
}

\author{
Jonas P. Ehrsam ${ }^{1}$, Ulrike Held ${ }^{2}$, Isabelle Opitz ${ }^{1}$, Ilhan Inci ${ }^{1}$ \\ ${ }^{1}$ Department of Thoracic Surgery, University of Zurich, University Hospital, Zurich, Switzerland; ${ }^{2}$ Department of Biostatistics at Epidemiology, \\ Biostatistics and Prevention Institute, University of Zurich, Zurich, Switzerland \\ Contributions: (I) Conception and design: I Inci, JP Ehrsam, U Held; (II) Administrative support: None; (III) Provision of study materials or patients: \\ None; (IV) Collection and assembly of data: JP Ehrsam; (V) Data analysis and interpretation: I Inci, JP Ehrsam, U Held; (VI) Manuscript writing: All \\ authors; (VII) Final approval of manuscript: All authors. \\ Correspondence to: Ilhan Inci, MD, FCCP, FEBTS. Professor of Thoracic Surgery, Department of Thoracic Surgery, University of Zurich, \\ Raemistrasse 100, 8091 Zurich, Switzerland. Email: ilhan.inci@usz.ch.
}

Background: Donor selection criteria are crucial for a successful lung transplant outcome. Our objective was to develop a new donor score to predict short- and long-term survival and validate it with five existing lung donor scores (Oto, Eurotransplant, Minnesota, Maryland-UNOS, Louisville-UNOS).

Methods: All 454 adult lung transplants at our center between 1992-2015 were included to develop a new score. Discriminative ability for all scores was calculated by the area under time-dependent receiver operating characteristic curves (time-dependent AUC) at 30-day, 1, 5 and 10-year survival, and their fit compared with Akaike's information criterion. For the new score, five pre-selected donor risk factors were derived: age, diabetes mellitus, smoking history, pulmonary infection, $\mathrm{PaO}_{2} / \mathrm{FiO}_{2}$-ratio, weighed via simplification of a multiple Cox model, and shrinkage used to avoid overfitting. The score sub-weighting resulted in a total of 17 points.

Results: The existing scores showed predictive accuracy better than chance in prediction of survival of 5-year (AUC 0.58-0.60) to 10-year survival (AUC 0.58-0.64). Our new score had better discriminative ability as the existing scores with regard to 1, 5 and 10-year survival (AUC 0.59, 0.64, 0.66, respectively). Additional adjustment for recipient and surgical procedure variables improved the time-dependent AUC's slightly. For the secondary outcomes primary graft dysfunction and bronchiolitis obliterans syndrome, the new score showed also a good predictive accuracy.

Conclusions: The proposed Zurich Donor Score is simple, well adapted for the current urge of extended donors use, and shows higher discriminative ability compared to preexisting donor scores regarding short- to long-term survival.

Keywords: Lung transplantation; lung allocation; lung donor score; extended criteria donor; primary graft dysfunction; bronchiolitis obliterans syndrome

Submitted May 26, 2020. Accepted for publication Sep 04, 2020.

doi: $10.21037 /$ jtd-20-2043

View this article at: http://dx.doi.org/10.21037/jtd-20-2043

\section{Introduction}

Organ shortage and a growing demand for lung transplantations force several centers to increasingly use extended donor lungs. In 2003 the International Society for Heart and Lung Transplantation (ISHLT) released a consensus report (1) defining an ideal donor lung based on 5 variables: age $<55$, smoking history $<20$ pack years, uncompromised chest X-ray, clear bronchoscopy and pulmonary arterial oxygen tension/fraction of inspired oxygen-ratio $>300 \mathrm{mmHg}$.

In the meantime, several attempts were made to further specify and identify potential extended criteria. In 2007 Oto 
et al. (2) at the University of Melbourne suggested a score based on the ISHLT-criteria to predict donor selection and early post-lung-transplant outcome. In 2011 the Oto-Score was modified by the European allocation organization Eurotransplant (3) to a new score serving the same purpose. In 2016 the University of Minnesota (4) created a new, complex, consensus-based lung scoring system to predict lung offer acceptance and usability for transplantation. However, the University of Maryland (5) identified donor risk factors based on United Network for Organ Sharing (UNOS) data and created a single point score that was associated with one-year survival, based on just four simple risk factors. Lately, the University of Louisville (6) identified almost identical four risk factors in the same data base and showed an association with 1 and 5-year survival.

To date, only the Oto-Donor-Score has been externally validated with inconsistent results $(4,7)$. Except for the Louisville-UNOS donor score, nothing is known about the utility of any of these scores to predict long-term survival.

The goal of the current study was first, to validate the short- and long-term predictive ability of five published scores based on our centers transplant pool and second, to develop a new and simple donor score for survival that includes donor parameters prior to procurement. We present the following article in accordance with the TRIPOD reporting checklist (available at http://dx.doi. org/10.21037/jtd-20-2043).

\section{Methods}

We performed a retrospective study of all adult recipients and their corresponding donors transplanted at the University Hospital of Zurich between 11/1992 and $12 / 2015$, with last follow-up in 10/2019. Donor and recipient data were collected retrospectively from prospectively entered medical records. For donor variables, the values at the time of donor acceptance, prior to procurement were used. Infection suspected on radiological findings in the contralateral lung were ignored in cases where only unilateral transplants were performed. The collected donor variables were compared to findings in the donor report at the time of procurement. The study has been approved by the Cantonal Ethics Committee Zurich (KEK-ZH-Nr.2013-0624), and the need to obtain informed consent was waived because of the retrospective observational nature of the study. This study was conducted in accordance with the Declaration of Helsinki (as revised in 2013).

\section{Outcomes}

The primary outcome was survival after lung transplantation. Secondary outcomes were primary graft dysfunction grade 3 (PGD3) (8), defined as $\mathrm{PaO}_{2} / \mathrm{FiO}_{2}$-ratio $<200 \mathrm{mmHg}$ and the presence of diffuse parenchymal infiltrates in the allograft on chest radiograph at 72 hours after transplantation (binary outcome); as well as severe bronchiolitis obliterans syndrome grade III (BOS-III) (9), defined as a persistent decline of forced expiratory volume in 1 second (FEV1) $\leq 50 \%$ and an obstructive physiology (time-to-event).

\section{Definition of predictor variables}

\section{Variables of the existing donor scores}

The variables of the five existing donor scores are shown in Tables S1-S5. Oto-Score (2) consists of 5 subdivided donor criteria based on the ISHLT-Consensus Report (1). Eurotransplant-Score (3) is a simplified version of OtoScore with the addition of a compromised history. The University of Minnesota-Donor-Lung quality index (4) includes 17 subdivided factors of which one factor represents the recipient specific American Lung Allocation Score (LAS). As LAS is not used in Switzerland, we excluded LAS for this score but adjusted for recipient and surgical procedure variables subsequently. To make the results of the evaluation of the Minnesota score comparable to the results of the other scores, the scale was reversed such that higher values are associated with higher risk for mortality. University of Maryland-UNOS-data donor score (5) and Louisville-UNOS-data score (6) are very simple scores based on the same 4 variables, except that the later uses different breaks for age.

\section{Development of the Zurich-Donor-Score for prediction of mortality}

A larger and preliminary set of potential risk variables was defined consisting of all variables of the five existing donor scores (Tables S1-S5) and availability. A preselection of variables was performed according to the estimated hazard ratios (HR) and $\mathrm{P}$ values from univariate Cox regression models with outcome survival. If the corresponding HR was $\geq 1.2$ and $\mathrm{P}$ value $<0.2$, the predictor variable was assumed to be relevant for risk prediction (10). The final set of variables used to develop the new donor score included the following variables: significant pulmonary infection, diabetes mellitus, $\mathrm{PaO}_{2} / \mathrm{FiO}_{2}$-ratio, smoking history in pack 
years, and donor age. The three continuous variables were categorized by the study team according to multiple nonlinear graphical assessment using splines and consideration of the recent literature. After categorization of the continuous variables, all variables were coded as factor variables and their association with survival was assessed in a multiple Cox model. Resulting estimated beta-coefficients were shrinked globally to account for overfitting. Shrinkage is a statistical technique used in regression analysis, to avoid overfitting (11). Subsequently, the new score's values were assigned following the rule that estimated beta-coefficients of 0.1 to 0.2 were assigned two points, such of 0.3 three points, such of 0.4 four points, and higher beta-coefficients five points. Score points were assigned in monotonous fashion with increasing category of risk factor.

\section{Definition of recipient- and surgical procedure variables}

To consider the impact of recipient and surgical procedure variables on post-transplant survival, we adjusted our models for the following risk factors that are well known from the literature and also present in our cohort: unilateral transplantation (12), retransplantation (12), idiopathic pulmonary fibrosis as underling disease (12), preoperative intensive care unit stay (12), recipient age (12), and for the comorbidity profile the age independent Charlson-Deyo Index (13). No additional impact was observed by adjusting for up to 3 different transplant eras.

\section{Statistical methods}

Kaplan-Meier method was used to estimate survival as well as time to development of BOS-III.

To estimate short and long-term predictive accuracy for each score, time dependent receiver operating characteristic curves (ROC) were applied, accounting for the fact that censoring was present. The time points shown in figures were 1 month, and 1,5 and 10 years after transplantation. Areas under the ROC curves (AUC) were estimated at each of the pre-specified time points. To compare models' goodness of fit, Akaike's information criterion (AIC) was used, with lower AIC indicating better model fit. The AIC can be interpreted in such a way that a reduction of more than 2 points in the comparison of nested models would indicate a significantly better model fit, corresponding to a likelihood-ratio test.

For the development of a new score, multiple Cox proportional hazards models were used. The number of predictors allowed to be simultaneously in the multiple Cox models was based on the number of events (deaths). The general rule of ten events per variable in the prediction model was considered (14). To address the problem of overfitting, the estimated coefficients of the Cox model were shrinked globally, with a shrinkage factor estimated with the DFBETA method (15). In this context, global shrinkage means that the same amount of shrinkage was applied to all estimated parameters. The assessment of the shrinkage factor with the DFBETA method corresponds to leaveone-out cross-validation (LOOCV) but is computationally more efficient. This aspect is of relevance especially when the number of observations is large as in this study (16). The closer the shrinkage factor to 1 , the less shrinkage is required and the less over-fitting was determined. The Cox proportional hazards $(\mathrm{PH})$ assumption was evaluated with a score test based on Schoenfeld residuals. In case that the proportional hazards assumption for a variable was violated, a suitable cut-off for the variable was derived, and the proportional hazards assumption was re-evaluated.

For secondary outcomes, BOS-III was addressed with a Cox model in which non-survivors were censored, and the binary outcome PGD3 was addressed with a logistic regression model. All estimated coefficients were shown with $95 \%$ confidence intervals. All analyses were carried out with the statistical programming language $\mathrm{R}$ [R Core Team (2019)], version 3.6.0, and time-dependent ROC curves were fitted with the R-package "timeROC". Shrinkage was performed with R-package "shrink".

The results of this study were presented in accordance with the TRIPOD guidelines (17) for reporting of clinical prediction models.

\section{Results}

In our cohort, there were 454 adult recipients with lung transplantation between 1991 and 2015, and with at least 4 years follow-up. Of these, 320 recipients $(70.5 \%)$ died. Median follow-up time was 14.2 years (95\% confidence interval 12.4 to 16.0 years). No loss to follow-up occurred. Detailed descriptive statistics of recipient-, donor-, intraand post-operative characteristics are shown in Table 1. More than $72 \%$ of all donors were non-ideal donors according to ISHLT consensus criteria (1) (Table 1).

\section{Validation of the five existing donor scores in our cohort}

Factors for Oto-Donor-Score (2), Eurotransplant-Score (3), 
Table 1 Baseline recipient, donor, peri and post-operative

\begin{tabular}{|c|c|}
\hline Characteristics & Outcome \\
\hline \multicolumn{2}{|l|}{ Recipient characteristics } \\
\hline $\mathrm{N}$ & 454 \\
\hline Age (years), median (range) & $48(16-70)$ \\
\hline Male gender & $232(51.1 \%)$ \\
\hline \multicolumn{2}{|l|}{ Diagnosis (all) } \\
\hline CF & $147(32.4 \%)$ \\
\hline EMP & $132(29.1 \%)$ \\
\hline $\mathrm{PPH}$ & 27 (5.9\%) \\
\hline IPF & $90(19.8 \%)$ \\
\hline Other & $58(12.8 \%)$ \\
\hline ICU admission pre-operative & $43(9.5 \%)$ \\
\hline mPAP $>25 \mathrm{mmHg}$ & $235(51.8 \%)$ \\
\hline Waitlist time (days), median (range) & $150(0-1,965)$ \\
\hline $\begin{array}{l}\text { Charlson-Deyo Comorbidity index (12), } \\
\text { median (range) }\end{array}$ & $1(0-4)$ \\
\hline 2 & $125(27.5 \%)$ \\
\hline 3 & 45 (9.9\%) \\
\hline 4 & $16(3.5 \%)$ \\
\hline 5 & $3(0.7 \%)$ \\
\hline \multicolumn{2}{|l|}{ Donor characterisics } \\
\hline Age (years), median (range) & $45(11-85)$ \\
\hline Charlson-Deyo index (12), median (range) & $0(0-5)$ \\
\hline 1 & $42(9.3 \%)$ \\
\hline 2 & $7(1.5 \%)$ \\
\hline 3 & $5(1.1 \%)$ \\
\hline 4 & $5(1.1 \%)$ \\
\hline 5 & $1(0.2 \%)$ \\
\hline \multicolumn{2}{|l|}{ Cause of death } \\
\hline \multicolumn{2}{|l|}{ Cranial bleeding/ischemia } \\
\hline Traumatic & $165(36.3 \%)$ \\
\hline Atraumatic & $230(50.7 \%)$ \\
\hline Asphyxiation & $51(11.2 \%)$ \\
\hline Other & $8(1.8 \%)$ \\
\hline CMV mismatch & $122(26.9 \%)$ \\
\hline
\end{tabular}

Table 1 (continued)
Table 1 (continued)

\begin{tabular}{lc}
\hline Characteristics & Outcome \\
\hline Extended criteria according to ISHLT (1) & \\
Age $\geq 55$ years & $128(28.2 \%)$ \\
Smoking history $\geq 20$ packyears & $77(17.0 \%)$ \\
Chest X-Ray pathologic & $122(26.9 \%)$ \\
Bronchoscopy pathologic & $50(11.0 \%)$ \\
PaO2-FiO Ratio <300 mmHg & $171(37.7 \%)$ \\
Number, median (range) & $1(0-4)$ \\
1 & $161(35.5 \%)$ \\
2 & $123(27.1 \%)$ \\
3 & $39(8.6 \%)$ \\
4 & $6(1.3 \%)$ \\
Peri and post-operative characteristics & \\
Unilateral transplantation & $36(7.9 \%)$ \\
Retransplantation & $19(4.2 \%)$ \\
ECMO use & $186(41.0 \%)$ \\
Donor cardiac after circulatory death & $16(13.5 \%)$ \\
ICU time (days), median (range) & \\
\hline PGD Grade3 at 72 hours & $132-885)$ \\
\hline
\end{tabular}

PGD, primary graft dysfunction; CMV, Cytomegalovirus; ICU, intensive care unit; ECMO, extracorporal membrane oxygenation; mPAP, mean pulmonary artery pressure; CF, cystic fibrosis; IPF, interstitial pulmonary fibrosis; $\mathrm{PPH}$, primary pulmonary hypertension; EMP, emphysema.

Minnesota-Donor-Lung quality index (4), MarylandUNOS-data donor score (5) and Louisville-UNOS-data donor score (6) are illustrated in Tables S1-S5, respectively.

Akaike's information criterion revealed best model fit for predictability for Maryland-UNOS-data donor score with an AIC value of 3,414.4, followed by lower fit for LouisvilleUNOS-data donor score (AIC 3,414.9), Minnesota-DonorLung quality index (AIC 3,417.8), Oto-Donor-Score (AIC $3,425.1$ ) and finally the lowest fit for Eurotransplant-Score (AIC 3,426.3).

\section{Development of the Zurich-Donor-Score}

A multiple Cox model was used to evaluate the weight of 
A

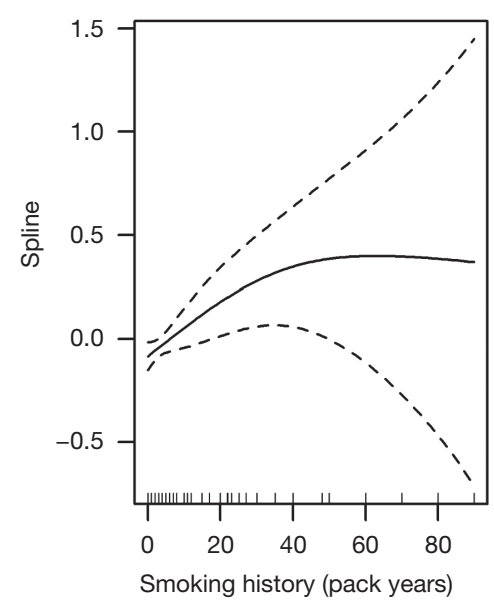

B

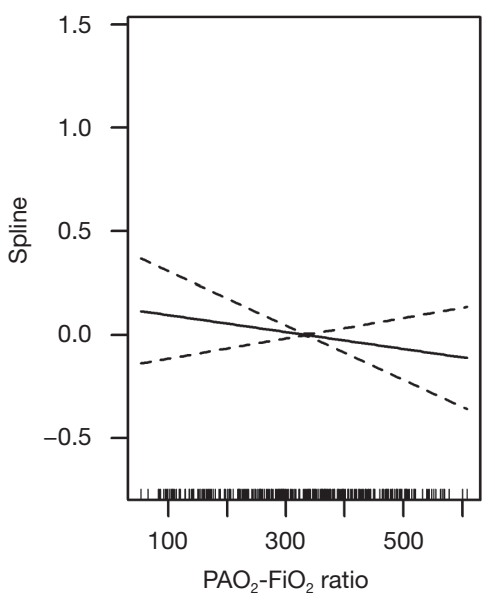

C

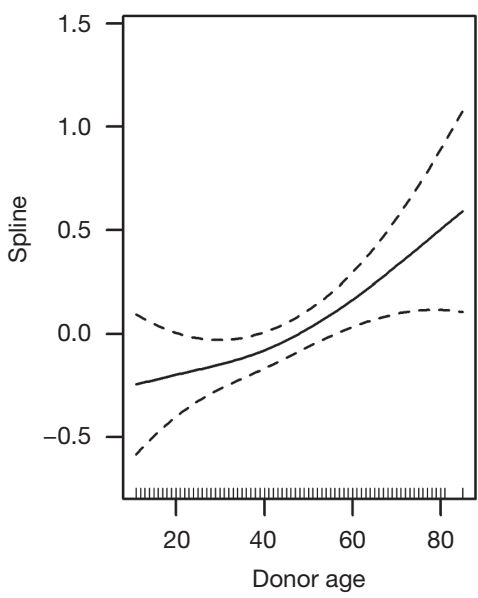

Figure 1 Additive non-linear effects using splines of the continuous variables in multiple Cox regression models. (A) Smoking history, (B) $\mathrm{PaO}_{2} / \mathrm{FiO}_{2}$-ratio and (C) donor age.

significant pulmonary infection, diabetes mellitus, $\mathrm{PAO}_{2} /$ $\mathrm{FiO}_{2}$-ratio (in categories with breaks at 300 and $150 \mathrm{mmHg}$ ), smoking history (in categories with breaks at 20 and 50 pack years), and donor age (with breaks at 50 and 70 years). The breaks in the continuous variables were justified from fitting multiple non-linear Cox models using splines (Figure 1) and by the literature. After the multiple Cox model was fitted based on the categorical variables, there was some indication for overfitting, resulting in a global estimated shrinkage factor of 0.82 . The new score varied between 0 (low mortality risk) and 12 (high mortality risk) in our sample, whereas mean and median of the new score were 3.3 and 3. Details can be found in Table 2. Figure $2 A$ and Table 3 show the results of a time-dependent ROC analysis of the new Zurich-Donor-Score as compared to the existing donor scores. The AIC value of the ZurichDonor-Score was 3,398.9, which was lower than those of all existing donor score, indicating better model fit.

\section{Assessing the predictive accuracy of all donor scores while adjusting for recipient and surgical procedure variables}

Recipient and surgical procedure variables included unilateral transplantation, retransplantation, idiopathic pulmonary fibrosis as underling disease, preoperative intensive care unit stay, recipient age, and age independent Charlson-Deyo Index. Figure $2 B$ showed that recipient and surgical procedure variables are crucial in order to make predictions of survival over time. After one month, donor and receiver information seem to be almost equally important, but as time passes, recipient and surgical procedure information from baseline become more important, leading to a substantially improved AUC for all scores at 10 years follow-up time. In a multiple Cox model with adjustment for recipient and surgical procedure variables, the estimated hazard ratio for the new score was 1.14 (95\% CI: 1.09 to $1.19, \mathrm{P}<0.001$ ) per point increase.

\section{Secondary outcomes: time to BOS-III and PGD3}

Although the new donor score was originally developed for the short- and long-term prediction of mortality after lung transplantation, the score may also be evaluated for the secondary outcomes BOS-III and PGD3. BOS-III was developed by 168 (37\%) of the recipients. In a multiple Cox model with adjustment for recipient and surgical procedure variables, the estimated hazard ratio for the new score was 1.14 (95\% CI: 1.07 to $1.21, \mathrm{P}<0.001)$ per point increase. Seventy-five percent recipients (17\%) experienced PGD3. When the new score was evaluated in a multiple logistic regression model with PGD3 as outcome, again adjusting for recipient and surgical procedure variables, the estimated odds ratio was 1.13 (95\% CI: 1.03 to $1.23, \mathrm{P}=0.01)$.

\section{Discussion}

Our study validates five existing donor scores in terms of short- and long-term survival, which were originally 
Table 2 Development of Zurich Donor Score based on estimated $\beta$-coefficients from multiple Cox model and shrinked coefficients

\begin{tabular}{|c|c|c|c|c|c|}
\hline Predictor & $\mathrm{N}$ & $\mathrm{HR}(95 \% \mathrm{Cl})$ & $\beta$ & Shrinked $\beta$ & $\begin{array}{l}\text { Score points Zurich donor } \\
\text { score (total } 17 \text { points) }\end{array}$ \\
\hline \multicolumn{6}{|c|}{ Significant pulmonary infection* } \\
\hline Yes & 127 & $1.46(1.14-1.87)$ & 0.38 & 0.31 & 3 \\
\hline No & 327 & - & - & - & 0 \\
\hline No & 429 & - & - & - & 0 \\
\hline \multicolumn{6}{|c|}{$\mathrm{PaO} 2 / \mathrm{FiO} 2$-ratio (mmHg) } \\
\hline$>300$ & 278 & - & - & - & 0 \\
\hline$<20$ & 377 & - & - & - & 0 \\
\hline 20 to $<50$ & 69 & $1.43(0.60-3.50)$ & 0.36 & 0.29 & 3 \\
\hline$\geq 50$ & 8 & $1.63(1.22-2.18)$ & 0.49 & 0.4 & 4 \\
\hline \multicolumn{6}{|l|}{ Age (years) } \\
\hline$<50$ & 273 & - & - & - & 0 \\
\hline 50 to $<70$ & 151 & $1.31(1.02-1.68)$ & 0.27 & 0.22 & 2 \\
\hline$\geq 70$ & 30 & $2.24(1.44-3.50)$ & 0.81 & 0.66 & 5 \\
\hline
\end{tabular}

$\beta, \beta$-coefficient; $\mathrm{Cl}$, confidence interval; HR, hazard ratio. * Radiological suspicion of pneumonia, bronchoscopic sign of severe bronchitis, history of aspiration (radiological suspicion of pneumonia: opacity in one or more lobes not predominantly resembling in morphology to atelectasis or edema; Signs of severe bronchitis: purulent secretions and/or signs of bronchial inflammation in bronchoscopy; History of aspiration: observed aspiration, signs in bronchoscopy of aspiration or a history highly suspicious of aspiration).

A

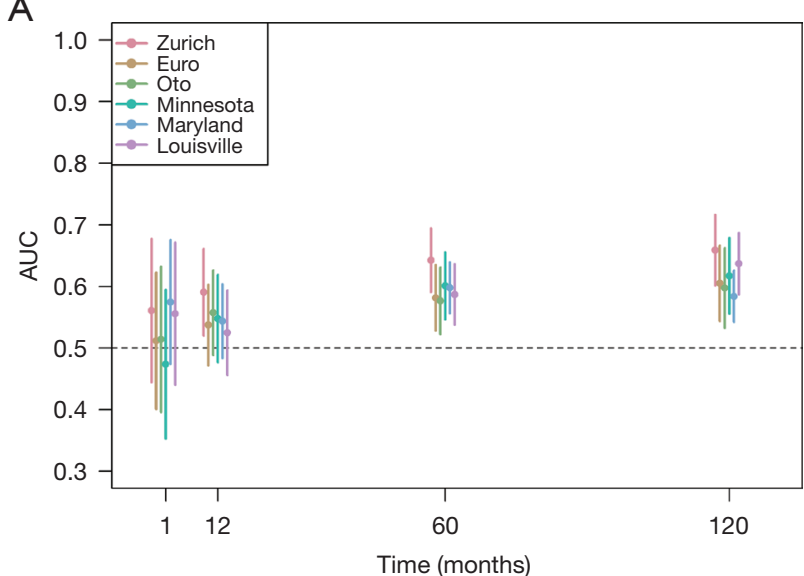

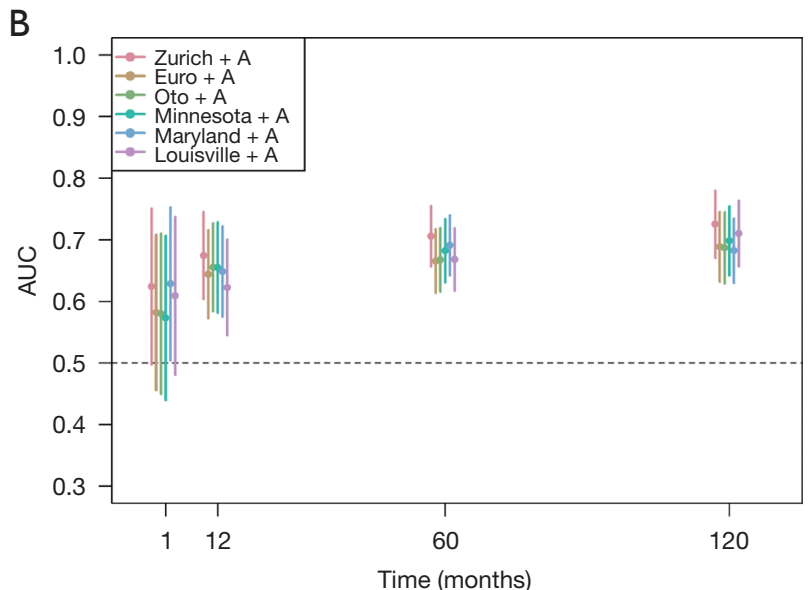

Figure 2 Time dependent AUC values for the five existing donor scores and the new Zurich-Donor-Score. (A) Unadjusted, based on donor information alone; (B) adjusted for recipient and surgical procedure variables. A = adjustment for recipient and surgical procedure variables. 
Table 3 Time dependent AUC values based on donor information alone

\begin{tabular}{|c|c|c|}
\hline & AUC & SE \\
\hline \multicolumn{3}{|c|}{ Zurich Donor Score } \\
\hline 30 days & 0.56 & 0.06 \\
\hline 1 year & 0.59 & 0.04 \\
\hline 5 years & 0.64 & 0.03 \\
\hline 10 years & 0.66 & 0.03 \\
\hline \multicolumn{3}{|c|}{ Eurotransplant Score (3) } \\
\hline 30 days & 0.51 & 0.06 \\
\hline 1 year & 0.54 & 0.03 \\
\hline 5 years & 0.58 & 0.03 \\
\hline 10 years & 0.61 & 0.03 \\
\hline \multicolumn{3}{|c|}{ Oto Donor Score (2) } \\
\hline 30 days & 0.51 & 0.06 \\
\hline 1 year & 0.56 & 0.04 \\
\hline 5 years & 0.58 & 0.03 \\
\hline 10 years & 0.6 & 0.03 \\
\hline \multicolumn{3}{|c|}{ Minnesota-Donor-Lung quality index (4) } \\
\hline 30 days & 0.47 & 0.06 \\
\hline 1 year & 0.55 & 0.04 \\
\hline 5 years & 0.6 & 0.03 \\
\hline 10 years & 0.62 & 0.03 \\
\hline \multicolumn{3}{|c|}{ Maryland-UNOS-data donor score (5) } \\
\hline 30 days & 0.58 & 0.05 \\
\hline 1 year & 0.54 & 0.03 \\
\hline 5 years & 0.6 & 0.02 \\
\hline 10 years & 0.58 & 0.02 \\
\hline \multicolumn{3}{|c|}{ Louisville-UNOS-data donor score (6) } \\
\hline 30 days & 0.56 & 0.06 \\
\hline 1 year & 0.53 & 0.04 \\
\hline 5 years & 0.59 & 0.03 \\
\hline 10 years & 0.64 & 0.03 \\
\hline
\end{tabular}

AUC, area under the ROC curve; SE, standard error.

developed to simplify donor selection and to predict shortto mid-term survival. In addition, we propose a new and simple scoring system that is well adapted for the current urge of extended donor use and shows higher discriminative ability for short- to long-term survival.

Our transplant center in Switzerland has long-term experience in utilizing extended criteria donor lungs (18). The recent lung acceptance rate of $46 \%$ is higher than in most other European centers and the United States, but the long-term survival results are comparable (19). More than $70 \%$ of all recipients in our study received a not ideal donor lung based on the ISHLT-consensus criteria (1), offering good conditions for validation of existing donor scores and the derivation of a new scoring system.

\section{Qualitative summary of the existing donor scores}

The relatively complex donor scoring systems of Oto (2), Eurotransplant (3) and Minnesota (4), which were originally created to predict donor selection, lead to a slightly poorer prediction of short- and long-term survival as did the simple Maryland-UNOS-data (5) and Louisville-UNOS-data score (6), which were derived to predict short-term survival and mid-term survival, respectively.

\section{Qualitative summary of the Zurich-Donor-Score}

For our new and simple extended donor prediction score, we identified and weighted five donor risk factors that are available at the time of donor selection: age (breaks at $\geq 50$ and $\geq 70$ years), smoking history (breaks at $\geq 20$ and $\geq 50$ pack years), significant pulmonary infection, insulin dependent diabetes mellitus and $\mathrm{PaO}_{2} / \mathrm{FiO}_{2}$-ratio (breaks at $\leq 300$ and $\leq 150 \mathrm{mmHg}$ ).

Increasing donor age has an increasing negative impact on survival according to our findings which is comparable with the recent ISHLT-Registry Report (12). Our lower break of 50 or more years fits the start of risk of a large study using the UNOS-Database (20).

The observed increasing risk with increasing donor smoking history fits the idea of the donor scoring systems of Oto (2). The lower break of 20 or more pack years is in agreement with the ISHLT-consensus criteria (1) and a recent study using UNOS-Data (4).

Our risk factor of a significant pulmonary infection includes radiological findings suspicious of pneumonia, bronchoscopic signs of severe bronchitis and history of aspiration. These were defined as extended criteria according to ISHLT-consensus report (1). We combined and reduced these criteria, as their impact is to a certain extent controversial. Some studies have pointed out that lungs with radiological hints of pulmonary infiltrates did 
not affect transplant survival $(21,22)$. Other studies showed that radiological abnormalities and additional purulent bronchoscope secretion (23) and radiological abnormalities and additional reduced gas exchange (18) did increase mortality.

Donor diabetes mellitus is a widely accepted $(5,12)$ risk factor, even though the pathophysiology is not yet clearly known (24).

Our detected risk of a declining $\mathrm{PaO}_{2} / \mathrm{FiO}_{2}$-ratio form $300 \mathrm{mmHg}$ downwards fits the recommendation of the ISHLT-consensus criteria (1). While a multicenter study found an impact (25), data from UNOS (26) suggest partial pressure of oxygen levels of lower than $200 \mathrm{mmHg}$ do not affect graft survival. That's why we weighted this factor proportionally low in our score.

Our final Zurich-Donor-Score showed better prediction of 1 to 10 -year survival in comparison to the five existing scores.

Although this new donor score was originally developed for the short- and long-term prediction of mortality after lung transplantation, the score also showed predictability for development of BOS-III and PGD3. This may be explained to a certain extent by the incorporated risk factors of age and smoking history. Older age was identified as a risk factor for BOS-III in some studies $(27,28)$, while it is still controversial in causing PGD3 (29,30). Any donor smoking was reported to have an association with BOS-III (27) and a negative impact on PGD3 (31). The significance of donor lung infection for PGD3 is not yet understood (32).

\section{Limitations and strengths}

This study has several limitations. It is a retrospective single-center study over more than two decades, however without an era effect in univariable and multiple analyses, even though we stratified in different models up to 3 eras. All donor variables and subsequent calculation of scores are based on pre-procurement parameters. Although we did not find any discrepancies between these values and the donor lung reports at the time of retrieval, the values might not account for exact results of the physical examination of the lung at the time of retrieval (33). We acknowledge that variables such as the interpretations of chest $\mathrm{X}$-ray and bronchoscopy are to some extent subjective. As our data collection is limited, there might have been some other important donor variables, which were not found to be important, because their prevalence was low in our setting. For example, we were not able to include data from the
African race, a variable which is part of the Maryland- and Louisville-UNOS-data donor score. We also acknowledge that performance of the original Minnesota-Donor-Lung quality index including LAS might have been superior to our compensative adjustment for recipient and surgical procedure variables. Our study has several strengths: we used shrinkage of estimated coefficients prior to the development of the new score, a method to reduce overfitting that would otherwise lead to low predictive performance in new data sets. Consequently, this approach of shrinkage manages to already preclude optimism of the score without the need of a separate validation cohort

\section{Conclusions}

The proposed Zurich-Donor-Score is a simple scoring system of five objective and easily available pre-procurement donor variables. The new score shows higher discriminative ability when compared to existing donor scores regarding short- to long-term survival. This score is not yet evaluated for organ acceptance; this is currently being studied. In the reality of severe organ shortage and urge for more extended grafts, our proposed new score may be useful for clinical decision making in donor selection, allocation to specific recipient populations, comparison of data across centers, and thereby maximize the donor pool.

\section{Acknowledgments}

Funding: None.

\section{Footnote}

Reporting Checklist: The authors have completed the TRIPOD reporting checklist. Available at http://dx.doi. org/10.21037/jtd-20-2043

Data Sharing Statement: Available at http://dx.doi. org/10.21037/jtd-20-2043

Conflicts of Interest: All authors have completed the ICMJE uniform disclosure form (available at http://dx.doi. org/10.21037/jtd-20-2043). The authors have no conflicts of interest to declare.

Ethical Statement: The authors are accountable for all aspects of the work in ensuring that questions related to the accuracy or integrity of any part of the work are 
appropriately investigated and resolved. The study has been approved by the Cantonal Ethics Committee Zurich (KEK-ZH-Nr. 2013-0624), and the need to obtain informed consent was waived because of the retrospective observational nature of the study. This study was conducted in accordance with the Declaration of Helsinki (as revised in 2013).

Open Access Statement: This is an Open Access article distributed in accordance with the Creative Commons Attribution-NonCommercial-NoDerivs 4.0 International License (CC BY-NC-ND 4.0), which permits the noncommercial replication and distribution of the article with the strict proviso that no changes or edits are made and the original work is properly cited (including links to both the formal publication through the relevant DOI and the license). See: https://creativecommons.org/licenses/by-nc-nd/4.0/.

\section{References}

1. Orens JB, Boehler A, Perrot Md, et al. A review of lung transplant donor acceptability criteria. J Heart Lung Transplant 2003;22:1183-200.

2. Oto T, Levvey BJ, Whitford H, et al. Feasibility and Utility of a Lung Donor Score: Correlation With Early Post-Transplant Outcomes. Ann Thorac Surg 2007;83:257-63.

3. Smits JM, van der Bij W, Van Raemdonck D, et al. Defining an extended criteria donor lung: an empirical approach based on the Eurotransplant experience. Transpl Int 2011;24:393-400.

4. Loor G, Radosevich DM, Kelly RF, et al. The University of Minnesota Donor Lung Quality Index: A ConsensusBased Scoring Application Improves Donor Lung Use. Ann Thorac Surg 2016;102:1156-65.

5. Mulligan MJ, Sanchez PG, Evans CF, et al. The use of extended criteria donors decreases one-year survival in high-risk lung recipients: A review of the United Network of Organ Sharing Database. J Thorac Cardiovasc Surg 2016;152:891-8.e2.

6. Whited WM, Trivedi JR, van Berkel VH, et al. Objective Donor Scoring System for Lung Transplantation. Ann Thorac Surg 2019;107:425-9.

7. Porro GA, Valenza F, Coppola S, et al. Use of the Oto Lung Donor Score to Analyze the 2010 Donor Pool of the Nord Italia Transplant Program. Transplant Proc 2012;44:1830-4.

8. Snell GI, Yusen RD, Weill D, et al. Report of the ISHLT
Working Group on Primary Lung Graft Dysfunction, part I: Definition and grading-A 2016 Consensus Group statement of the International Society for Heart and Lung Transplantation. J Heart Lung Transplant 2017;36:1097-103.

9. Meyer KC, Raghu G, Verleden GM, et al. An international ISHLT/ATS/ERS clinical practice guideline: diagnosis and management of bronchiolitis obliterans syndrome. Eur Respir J 2014;44:1479-503.

10. Sauerbrei $W$. The use of resampling methods to simplify regression models in medical statistics. J R Stat Soc Ser C Appl Stat 1999;48:313-29.

11. Dunkler D, Sauerbrei W, Heinze G. Global, Parameterwise and Joint Shrinkage Factor Estimation. J Stat Softw 2016;69:19.

12. Chambers DC, Cherikh WS, Harhay MO, et al. The International Thoracic Organ Transplant Registry of the International Society for Heart and Lung Transplantation: Thirty-sixth adult lung and heart-lung transplantation Report-2019; Focus theme: Donor and recipient size match. J Heart Lung Transplant 2019;38:1042-55.

13. Deyo RA, Cherkin DC, Ciol MA. Adapting a clinical comorbidity index for use with ICD-9-CM administrative databases. J Clin Epidemiol 1992;45:613-9.

14. Ogundimu EO, Altman DG, Collins GS. Adequate sample size for developing prediction models is not simply related to events per variable. J Clin Epidemiol 2016;76:175-82.

15. Verweij PJ, Van Houwelingen HC. Cross-validation in survival analysis. Stat Med 1993;12:2305-14.

16. Dunkler D, Sauerbrei W, Heinze G. Global, parameterwise and joint shrinkage factor estimation. J Stat Softw 2016;96:1-19.

17. Collins GS, Reitsma JB, Altman DG, et al. Transparent reporting of a multivariable prediction model for individual prognosis or diagnosis (TRIPOD): the TRIPOD statement. BMJ 2015;350:g7594.

18. Lardinois D, Banysch M, Korom S, et al. Extended donor lungs: eleven years experience in a consecutive series. Eur J Cardiothorac Surg 2005;27:762-7.

19. International figures on donation and transplantation 2014 [database on the Internet]2014. Available online: https://www.edqm.eu/sites/default/files/newsletter transplant_2015.pdf. Accessed: Mai 1, 2020

20. Grimm JC, Valero V, 3rd, Magruder JT, et al. A novel risk score that incorporates recipient and donor variables to predict 1-year mortality in the current era of lung transplantation. J Heart Lung Transplant 2015;34:1449-54. 21. Sundaresan S, Semenkovich J, Ochoa L, et al. Successful 
outcome of lung transplantation is not compromised by the use of marginal donor lungs. J Thorac Cardiovasc Surg 1995;109:1075-9; discussion 1079-80.

22. Bhorade SM, Vigneswaran W, McCabe MA, et al. Liberalization of donor criteria may expand the donor pool without adverse consequence in lung transplantation. J Heart Lung Transplant 2000;19:1199-204.

23. Pierre AF, Sekine Y, Hutcheon MA, et al. Marginal donor lungs: a reassessment. J Thorac Cardiovasc Surg 2002;123:421-7; discussion 427-8.

24. Reyes KG, Mason DP, Thuita L, et al. Guidelines for donor lung selection: time for revision? Ann Thorac Surg 2010;89:1756-64; discussion 1764-5.

25. Thabut G, Mal H, Cerrina J, et al. Influence of donor characteristics on outcome after lung transplantation: a multicenter study. J Heart Lung Transplant $2005 ; 24: 1347-53$.

26. Zafar F, Khan MS, Heinle JS, et al. Does donor arterial partial pressure of oxygen affect outcomes after lung transplantation? A review of more than 12,000 lung transplants. J Thorac Cardiovasc Surg 2012;143:919-25.

27. De Perrot M, Waddell TK, Shargall Y, et al. Impact of

Cite this article as: Ehrsam JP, Held U, Opitz I, Inci I. A new lung donor score to predict short and long-term survival in lung transplantation. J Thorac Dis 2020;12(10):5485-5494. doi: 10.21037/jtd-20-2043 donors aged 60 years or more on outcome after lung transplantation: results of an 11-year single-center experience. J Thorac Cardiovasc Surg 2007;133:525-31.

28. Hennessy SA, Hranjec T, Swenson BR, et al. Donor factors are associated with bronchiolitis obliterans syndrome after lung transplantation. Ann Thorac Surg 2010;89:1555-62.

29. Liu Y, Liu Y, Su L, et al. Recipient-related clinical risk factors for primary graft dysfunction after lung transplantation: a systematic review and meta-analysis. PLoS One 2014;9:e92773.

30. Baldwin MR, Peterson ER, Easthausen I, et al. Donor age and early graft failure after lung transplantation: a cohort study. Am J Transplant 2013;13:2685-95.

31. Diamond JM, Lee JC, Kawut SM, et al. Clinical risk factors for primary graft dysfunction after lung transplantation. Am J Respir Crit Care Med 2013;187:527-34.

32. Morrison MI, Pither TL, Fisher AJ. Pathophysiology and classification of primary graft dysfunction after lung transplantation. J Thorac Dis 2017;9:4084-97.

33. Martens A, Neyrinck A, Van Raemdonck D. Accepting donor lungs for transplant: let Lisa and Bob finish the job! Eur J Cardiothorac Surg 2016;50:832-3. 
Supplementary

Table S1 Oto-Donor-Score (2)

Points (total 18 points)

\section{Age (years)}

$<45$

45-54

55-59

$\geq 60$

Smoking history (pack-years)

$<20$

20-39

40-59

$\geq 60$

Chest X-ray

Clear
Minor
Opacity $\leq 1$ lobe
Opacity $>1$ lobe

Opacity $>1$ lobe

Secretions in bronchoscopy

$\begin{array}{ll}\text { None } & 0 \\ \text { Minor } & \\ \text { Moderate } & \end{array}$

$\mathrm{PaO}_{2} / \mathrm{FiO}_{2}(\mathrm{mmHg})$

$$
>450
$$

351-450

301-350

$\leq 300$

3

\section{0}

2

3
Univariable Cox regression HR; 95\% Cl

$P$ value

$\begin{array}{lr}0 & 221(48.7 \%) \\ 1 & 105(23.1 \%) \\ 2 & 48(10.6 \%) \\ 3 & 80(17.6 \%)\end{array}$

377 (83.0\%)

$56(12.3 \%)$

$16(3.5 \%)$

$1.6 ; 1.2-2.2$

0.002

$1.7 ; 1.0-2.9$

0.06

$5(1.1 \%)$

$\begin{array}{ll}1.1 ; 0.8-1.4 & 0.5 \\ 1.4 ; 1.0-2.0 & 0.05 \\ 1.5 ; 1.1-1.9 & 0.01\end{array}$

245 (54.0\%)

$90(19.8 \%)$

$0.9 ; 0.8-1.2$

0.6

$64(14.1 \%)$

$1.0 ; 0.8-1.3$

0.7

$55(12.1 \%)$

1.0; 0.7-1.4

0.9

384 (84.6\%)

$23(5.1 \%)$

17 (3.7\%)

$1.2 ; 0.9-1.7$

0.2

30 (6.6\%)

$1.2 ; 0.8-1.8$

0.3

$1.7 ; 1.1-2.7$

0.02

90 (19.8\%)

139 (30.6\%)

0.9; 0.7-1.2

0.7

55 (12.1\%)

$0.8 ; 0.6-1.2$

0.4

$170(37.4 \%)$

$1.2 ; 1.0-1.5$

0.08 
Table S2 Eurotransplant-Score (3)

\begin{tabular}{|c|c|c|c|c|}
\hline & Points (total 19 points) & cohort $(\mathrm{N}=454)$ & \multicolumn{2}{|c|}{ Univariable Cox regression } \\
\hline \multicolumn{5}{|l|}{ Age (years) } \\
\hline$<45$ and $45-54$ & 1 & $326(71.8 \%)$ & - & \\
\hline $55-59$ & 2 & $48(10.6 \%)$ & $1.4 ; 1.0-2.0$ & 0.05 \\
\hline \multicolumn{5}{|l|}{ Smoking history (pack-years) } \\
\hline Yes & 2 & 277 (61.0\%) & - & \\
\hline No & 1 & 177 (39.0\%) & $1.2 ; 1.0-1.6$ & 0.06 \\
\hline \multicolumn{5}{|l|}{ Chest X-ray } \\
\hline \multicolumn{5}{|l|}{ Secretions in bronchoscopy } \\
\hline Clear or nonpurulent & 1 & $405(89.2 \%)$ & - & \\
\hline Purulent & 2 & 27 (5.9\%) & $1.1 ; 0.8-1.7$ & 0.5 \\
\hline Inflammation & 3 & $22(4.8 \%)$ & $1.6 ; 1.0-2.7$ & 0.05 \\
\hline Visualized tumor & 5 & - & - & \\
\hline \multicolumn{5}{|l|}{$\mathrm{PaO}_{2} / \mathrm{FiO}_{2}(\mathrm{mmHg})$} \\
\hline$>450$ and $351-450$ & 1 & $216(47.6 \%)$ & - & \\
\hline $301-350$ & 2 & $68(15.0 \%)$ & $0.8 ; 0.6-1.2$ & 0.4 \\
\hline
\end{tabular}

$\mathrm{Cl}$, confidence interval; HR, hazard ratio. ${ }^{*}$ The donor history is compromised in case of malignancy, sepsis, drug abuse, meningitis, or a positive virology was registered 
Table S3 Minnesota-Donor-Lung quality index (4)

\begin{tabular}{|c|c|c|c|c|}
\hline & \multirow{2}{*}{$\begin{array}{l}\text { Points [possible range } \\
\text { of points }(0-48) \text { ] }\end{array}$} & \multirow{2}{*}{ Cohort $(\mathrm{N}=454)$} & \multicolumn{2}{|c|}{ Univariable Cox regression } \\
\hline & & & $\mathrm{HR} ; 95 \% \mathrm{Cl}$ & $P$ value \\
\hline \multicolumn{5}{|c|}{ 1. Anticipated ischemic time } \\
\hline$<6$ hours & 1 & 404 (89.0\%) & - & \\
\hline$\geq 6$ hours & 0 & $50(11.0 \%)$ & $1.0 ; 0.7-1.4$ & 0.9 \\
\hline \multicolumn{5}{|c|}{ 2. Risk of pneumonia } \\
\hline Low & 4 & $173(38.1 \%)$ & - & \\
\hline Moderate & 2 & $232(51.1 \%)$ & $1.0 ; 0.8-1.2$ & 0.9 \\
\hline High & 0 & $49(10.8 \%)$ & $1.1 ; 1.0-1.1$ & 0.2 \\
\hline \multicolumn{5}{|l|}{ 3. Donor age } \\
\hline $15-45$ years & 2 & 234 (51.5\%) & - & \\
\hline $46-65$ years & 1 & $178(39.2 \%)$ & $1.2 ; 0.9-1.5$ & 0.1 \\
\hline$>65$ years & 0 & $42(9.3 \%)$ & $1.9 ; 1.3-2.7$ & 0.001 \\
\hline \multicolumn{5}{|c|}{ 4. Risk of aspiration injury } \\
\hline Low & 3 & 411 (90.5\%) & - & \\
\hline Moderate & 2 & $28(6.2 \%)$ & $1.2 ; 0.8-1.7$ & 0.4 \\
\hline High & 0 & $15(3.3 \%)$ & $1.4 ; 0.7-2.9$ & 0.3 \\
\hline \multicolumn{5}{|c|}{ 5. Risk of preexisting lung disease } \\
\hline Low & 4 & $446(98.2 \%)$ & - & \\
\hline Moderate & 2 & $8(1.8 \%)$ & $1.0 ; 0.8-1.2$ & 0.9 \\
\hline High & 0 & - & - & \\
\hline \multicolumn{5}{|c|}{ 6. Risk of pulmonary edema } \\
\hline Low & 3 & 447 (98.5\%) & - & \\
\hline Moderate & 2 & $7(1.5 \%)$ & $1.7 ; 0.8-3.7$ & 0.1 \\
\hline High & 0 & - & - & \\
\hline \multicolumn{5}{|l|}{ 7. Risk of contusion } \\
\hline Low & 2 & $428(94.3 \%)$ & - & \\
\hline Moderate & 1 & $15(3.3 \%)$ & $0.7 ; 0.5-1.2$ & 0.2 \\
\hline High & 0 & $11(2.4 \%)$ & $1.0 ; 0.5-2.0$ & 0.9 \\
\hline \multicolumn{5}{|l|}{ 8. Blood gasses } \\
\hline Good & 3 & $284(62.6 \%)$ & - & \\
\hline Marginal & 0 & $170(37.4 \%)$ & $0.9 ; 0.9-1.0$ & 0.05 \\
\hline \multicolumn{5}{|l|}{ 9. Smoking history } \\
\hline$<30$ Pack-years & 2 & $397(87.4 \%)$ & - & \\
\hline$\geq 30$ Pack-years & 0 & $57(12.8 \%)$ & $1.7 ; 1.2-2.3$ & 0.001 \\
\hline \multicolumn{5}{|c|}{ 10. Anticipated procurement complexity } \\
\hline Simple & 2 & $415(91.4 \%)$ & - & \\
\hline Moderate & 1 & $36(7.9 \%)$ & $1.0 ; 0.6-1.5$ & 0.9 \\
\hline Complex & 0 & $3(0.7 \%)$ & - & \\
\hline \multicolumn{5}{|c|}{ 11. Risk of pulmonary malignancy } \\
\hline Low & 5 & $283(62.3 \%)$ & - & \\
\hline Moderate & 4 & $94(20.7 \%)$ & $1.1 ; 0.8-1.4$ & 0.7 \\
\hline High & 0 & $77(17.0 \%)$ & $1.6 ; 1.2-2.1$ & 0.001 \\
\hline \multicolumn{5}{|c|}{ 12. Risk of donor-transmitted diseases } \\
\hline Low & 4 & $452(99.6 \%)$ & - & \\
\hline Moderate & 3 & $2(0.4 \%)$ & - & \\
\hline High & 0 & - & - & \\
\hline \multicolumn{5}{|c|}{ 13. Risk of extrapulmonary malignancy } \\
\hline Low & 5 & $445(98.0 \%)$ & - & \\
\hline Moderate & 2 & $9(2.0 \%)$ & $0.9 ; 0.7-1.1$ & 0.2 \\
\hline High & 0 & - & & \\
\hline \multicolumn{5}{|c|}{ 14. Risk of positive retrospective HLA crossmatch } \\
\hline Low & 5 & 454 (100\%) & - & \\
\hline Moderate & 3 & - & & \\
\hline High & 0 & - & & \\
\hline 15. Risk of size mis & & & & \\
\hline Low & 3 & 294 (64.8\%) & & \\
\hline Moderate & 2 & $23(5.1 \%)$ & $1.1 ; 0.9-1.4$ & 0.3 \\
\hline High & 0 & $137(30.2 \%)$ & $1.3 ; 1.0-1.6$ & 0.06 \\
\hline
\end{tabular}

$\mathrm{Cl}$, confidence interval; HLA, human leukocyte antigen; HR, hazard ratio. 
Table S4 Maryland-UNOS-data donor score (5)

\begin{tabular}{|c|c|c|c|c|}
\hline & Points (total 4 points) & Cohort $(\mathrm{N}=454)$ & \multicolumn{2}{|c|}{ Univariable Cox regression } \\
\hline Age $\geq 65$ years & 1 & $42(9.3 \%)$ & $1.9 ; 1.3-2.7$ & 0.001 \\
\hline Smoking history $\geq 20$ packyears & 1 & $77(17.0 \%)$ & $1.7 ; 1.3-2.2$ & $<0.001$ \\
\hline Diabetes & 1 & $25(5.5 \%)$ & $1.8 ; 1.1-2.9$ & 0.01 \\
\hline
\end{tabular}

$\mathrm{Cl}$, confidence interval; HR, hazard ratio.

Table S5 Louisville-UNOS-data donor score (6)

\begin{tabular}{|c|c|c|c|c|}
\hline & Points (total 5 points) & Cohort $(\mathrm{N}=454)$ & \multicolumn{2}{|c|}{ Univariable Cox regression } \\
\hline \multicolumn{5}{|l|}{ Age, years } \\
\hline $51-60$ & 1 & $97(21.4 \%)$ & $1.3 ; 1.0-1.7$ & 0.05 \\
\hline$>60$ & 2 & $71(15.6 \%)$ & $1.5 ; 1.5-2.1$ & 0.005 \\
\hline Diabetes & 1 & $25(5.5 \%)$ & $1.8 ; 1.1-2.9$ & 0.01 \\
\hline African American race & 1 & - & - & \\
\hline
\end{tabular}

$\mathrm{Cl}$, confidence interval; HR, hazard ratio. 